\title{
MECHANICAL CHARACTERIZATION OF DIFFERENT ORIENTATION OF GLASS FIBRE REINFORCED POLYESTER MATRIX COMPOSITE
}

\author{
Puttaswamaiah.S ${ }^{1}$, Mirsafiulla ${ }^{2}$, Maruthi B $\mathbf{H}^{3}$, Sridhar ${ }^{4}$, Harish $\mathrm{B}^{5}$ \\ ${ }^{1}$ Research Scholar, Department of Mechanical Engineering, GCE, Ramanagaram \\ ${ }^{2}$ Professor, Department of Mechanical Engineering, GCE, Ramanagaram \\ ${ }^{3}$ Professor, Department of Mechanical Engineering, EWIT, Bangalore \\ ${ }^{4}$ PG Student, Department of IEM, JSSATE, Bangalore \\ ${ }^{5}$ P.G Student, Department of Mechanical Engineering, EWIT, Bangalore
}

\begin{abstract}
The purpose of this study is to evaluation of the mechanical characterisation such as tensile, compression and bending test and to conduct wear test. This study focus on preparation and testing of Polyester resin using glass fibre for different orientation. The Mechanical properties of the polyester changes gradually by changing the layers of fibres and for different orientation of glass fibre the property differs. The laminate is prepared of size 300*300*4mm size and specimens are prepared as per ASTM standard, different layers of glass fibres are one, two and three layers and the orientation of glass fibre is $30^{\circ}, 60^{\circ}$, and $90^{\circ}$. The glass fibre used is in fabric form. From the results which were obtained we can observed that three layers glass fibre for $90^{\circ}$ orientation has improved tensile strength and the compressive strength is found to be more for $60^{\circ}$ orientation of glass fibre. And the wear rate is also less for three layer of glass fibre for $90^{\circ}$ orientations.
\end{abstract}

Keywords: Glass Fibre/Polyesters Composites, Mechanical Characterisation of Polyester, Orientation of Glass Fibre.

\section{INTRODUCTION}

Composite material can be defined as the combination of two or more different materials which having dissimilar property. the composite materials the fibre which may be in the form of fabric which is reinforced in the material gives strength to the overall material and the matrix provides rigidity. Fibre glass which are reinforced in polymer are generally popular reinforced plastic material which are used in many industry. Depending upon the formation and their use, they may be fabricated into products which are light in weight, transparent, colourless or coloured, flat or shaped sheets with no limits on size of object can be made. The reinforcing fibre is available in different form, it may be in the form of fabric or long continuous or chopped fibres. Different types of fibres which are reinforced give different properties. The Properties are usually depending on how the fibre is lay into composites and which fibres are used. In this study we have used glass fibre in fabric form and it is known

\section{OBJECTIVE AND METHODOLOGY}

A. Objective: The main objective of this project is to know and evaluate the mechanical characteristics and to find wear of material.

B. Methodology: Following are the steps involved,

- Preparation of mould.

- Preparation of composite laminates for different orientations of glass fibre.

- Cutting the laminates.

- Conducting mechanical test.
- Conducting Pin-on-disc wear test

\section{EXPERIMENTAL PROCEDURE}

The hand layup method is one of the efficient processes for developing of PMC's products. The first step is to calculate the amount of material required in the preparation of laminate of required size. The calculated amount of polyester resin with additive $\left(\right.$ caso $\left._{4}\right)$, catalyst and accelerator is mixed in a bowl. the laminate is prepared for 1 layer, 2 layers and 3 layers of glass fibre. The mixed materials is poured in a prepared mould and glass fibre is placed on the resin. For 1 layer laminate, only 1 layer of glass fibre is placed on the poured resin in the mould and the remaining resin is again poured over the glass fibre. The procedure will remain same for 2 layers and for 3 layers.

\section{SPECIMEN PREPARATION}

A. Tensile test: Tensile test was performed to calculate the ultimate tensile strength. Specimen dimensions are $228 \mathrm{~mm}$ in length, $25 \mathrm{~mm}$ in width and $4 \mathrm{~mm}$ thickness.



Figure 1: Tensile test specimen 


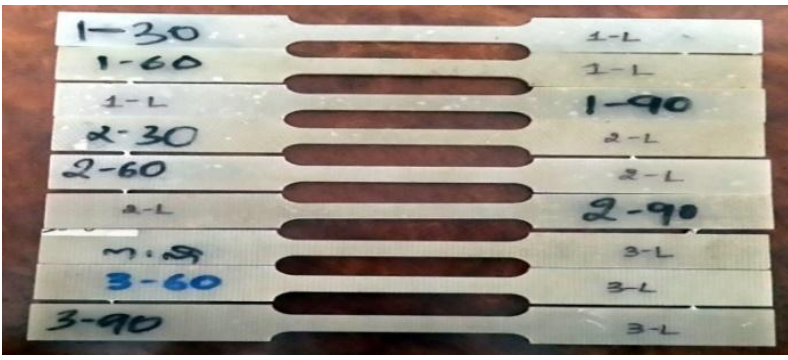

Figure 2: Tensile test specimen for different layers of glass fibres.

A. Compression test: In this test the material is compressed till the material is able to withstand not causing fracture in the material. The specimen dimensions are $127 \mathrm{~mm}$ in length, $10 \mathrm{~mm}$ in width and $4 \mathrm{~mm}$ in thickness.

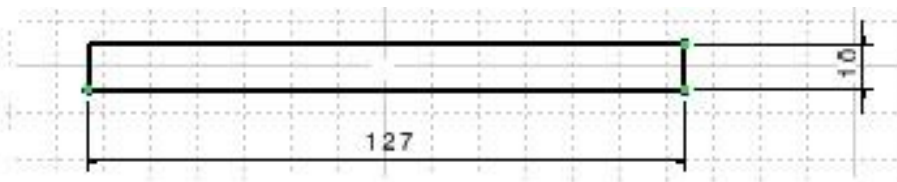

Figure 3: Compression test specimen.

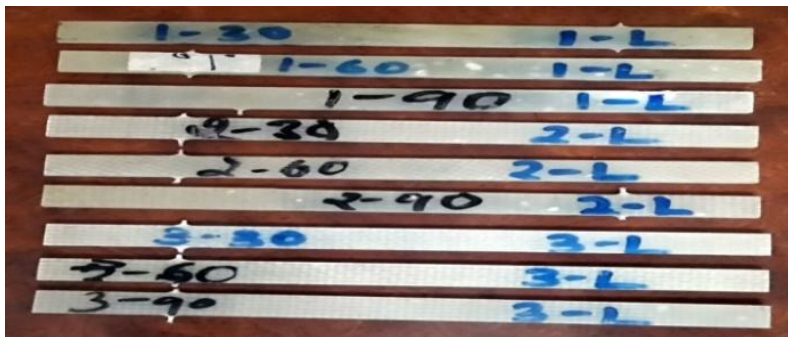

Figure 4: Compression test specimen for different layers of glass fibres.

B. Bending test: The specimen dimensions are $80 \mathrm{~mm}$ in length, $20 \mathrm{~mm}$ in width and $4 \mathrm{~mm}$ in thickness.

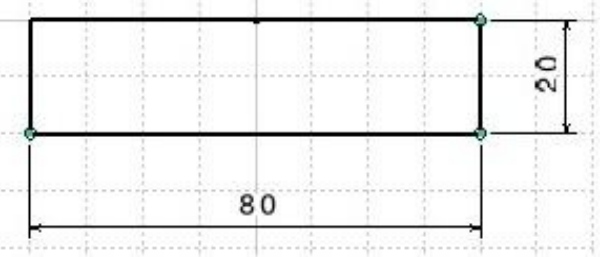

Figure 5: Bending test specimen.

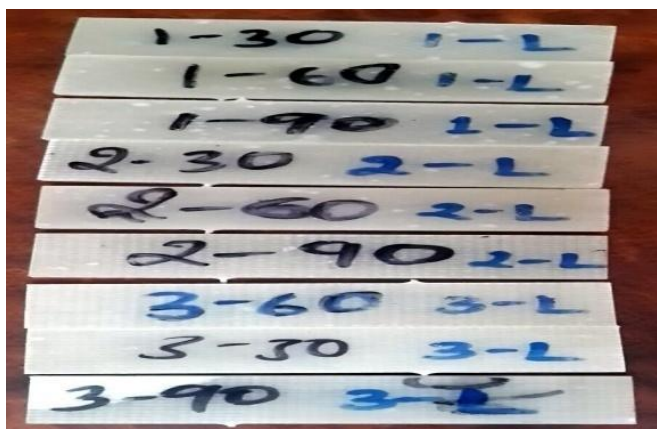

Figure 6: Bending test specimen for different layers of glass fibres.

\section{WEAR TEST}

A. Pin-on-disc wear test: Wear is simply defined as contact of material surfaces which causes deformation of material. The wear testing was carried out at a constant revolving speed 200rpm with constant load 20N. The speed and load was kept constant but the time was shifting. The test was carried out for three trails for $2 \mathrm{~min}, 4 \mathrm{~min}$ and $6 \mathrm{~min}$. The figure below shows the specimen size.

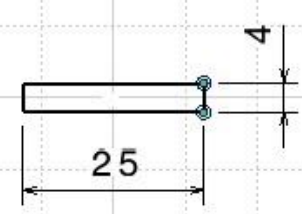

Figure 7: Wear test specimen.

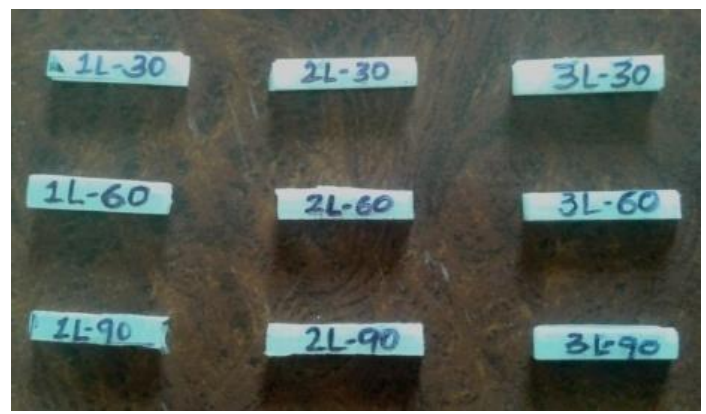

Figure 8: Wear test specimen fordifferent layers of glass fibres before testing.

\section{RESULTS AND GRAPHS}

\section{A. Tensile test:}

Tensile test is conducted for the prepared specimens for 1 layer, 2 layers and for 3 layers glass fibres for different orientations. The test speed was $5 \mathrm{~mm} / \mathrm{min}$ and the graph generated is shown below,

For 1 layer of glass fibre

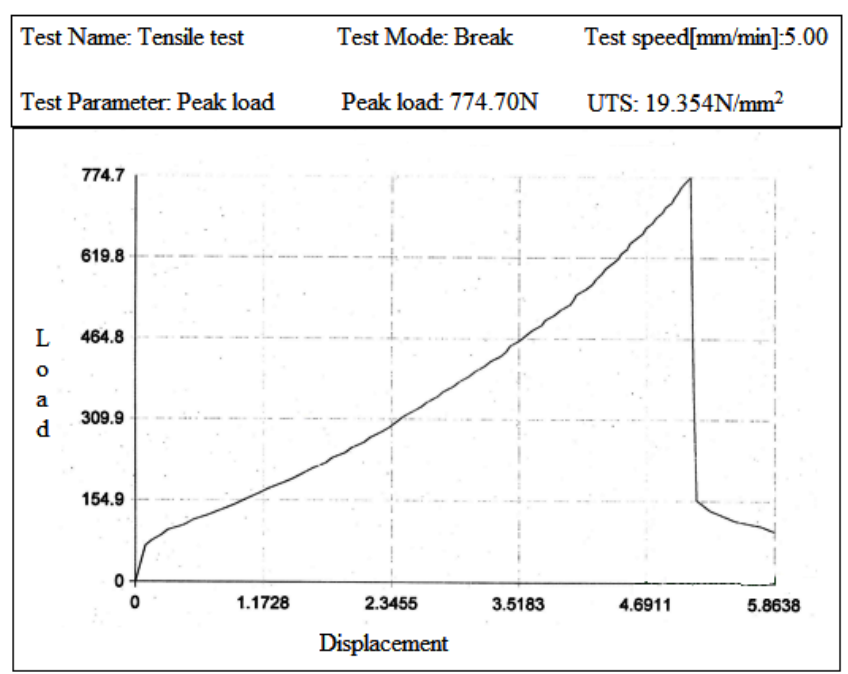

Figure 9: Tensile test graph for 1layer of glass fibre for $30^{\circ}$ orientation. 


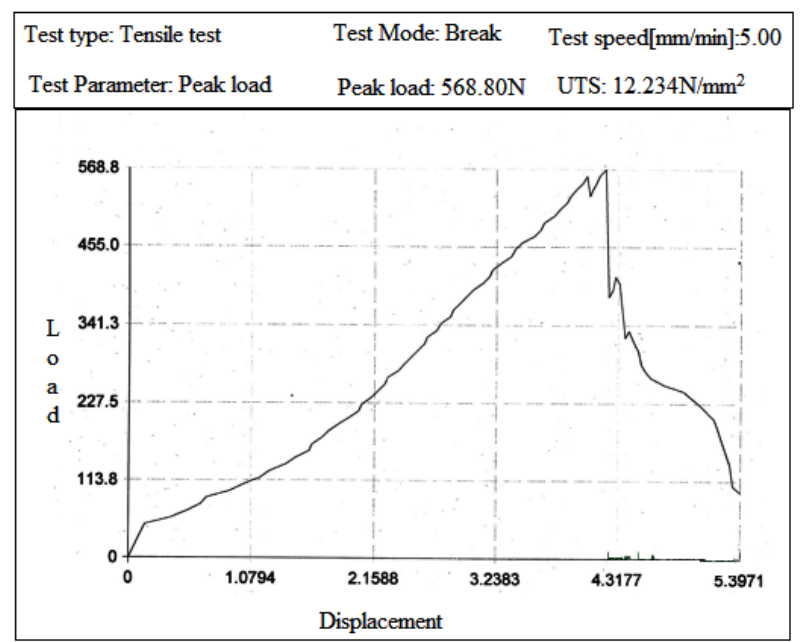

Figure 10: Tensile test graph for 1layer of glass fibre for $60^{\circ}$ orientation.

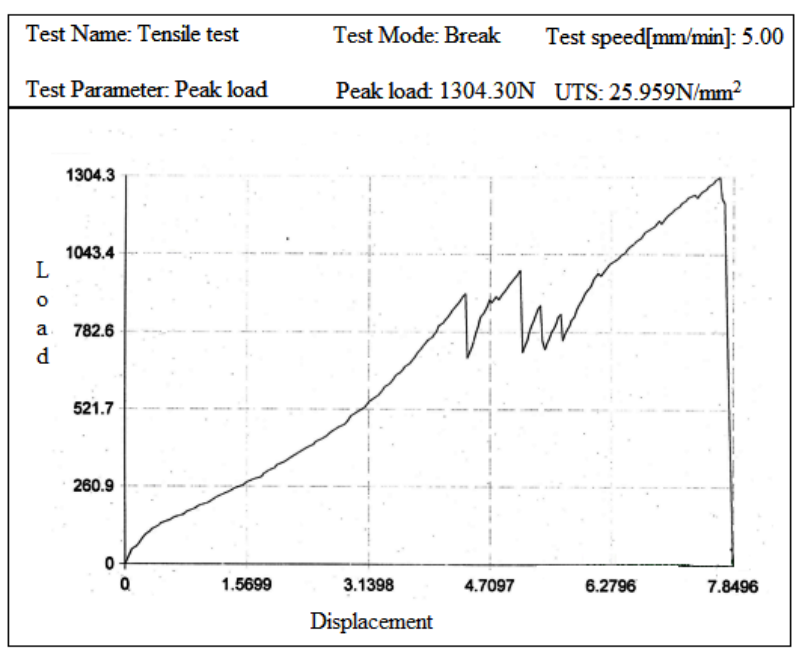

Figure 11: Tensile test graph for 1layer of glass fibre for $90^{\circ}$ orientation. For 2 layers of glass fibre.



Figure 12: Tensile test graph for 2layer of glass fibre for $30^{\circ}$ orientation.

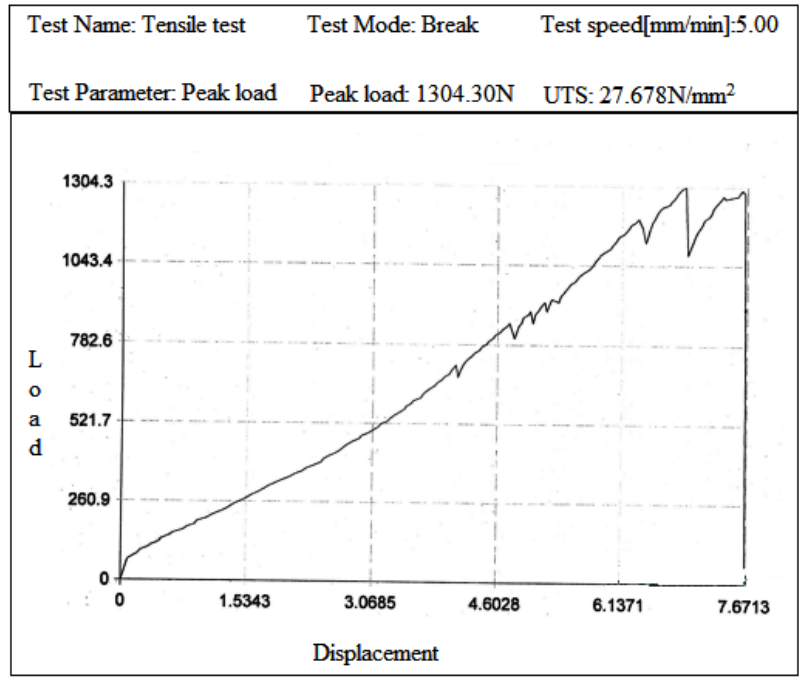

Figure 13: Tensile test graph for 2layer of glass fibre for $60^{\circ}$ orientation.

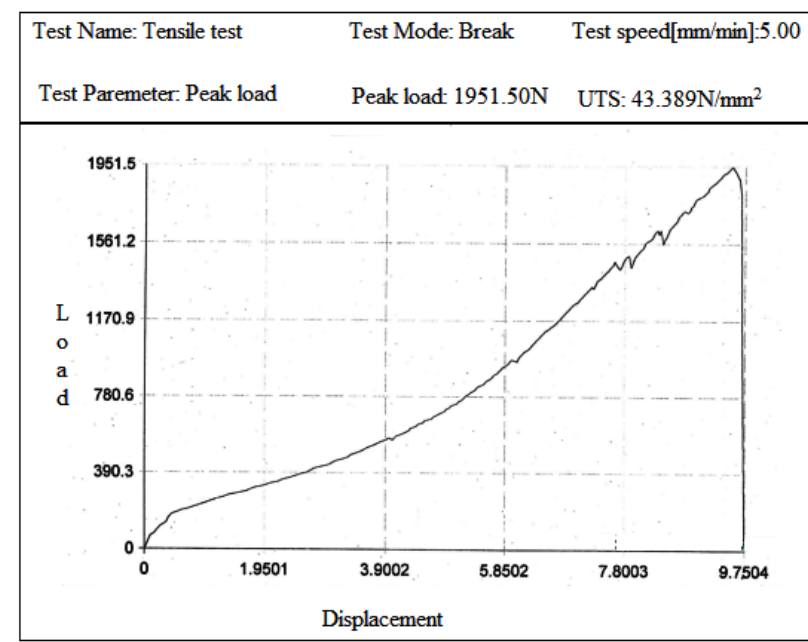

Figure 14: Tensile test graph for 2layer of glass fibre for $90^{\circ}$ orientation. For 3 layers of glass fibre.

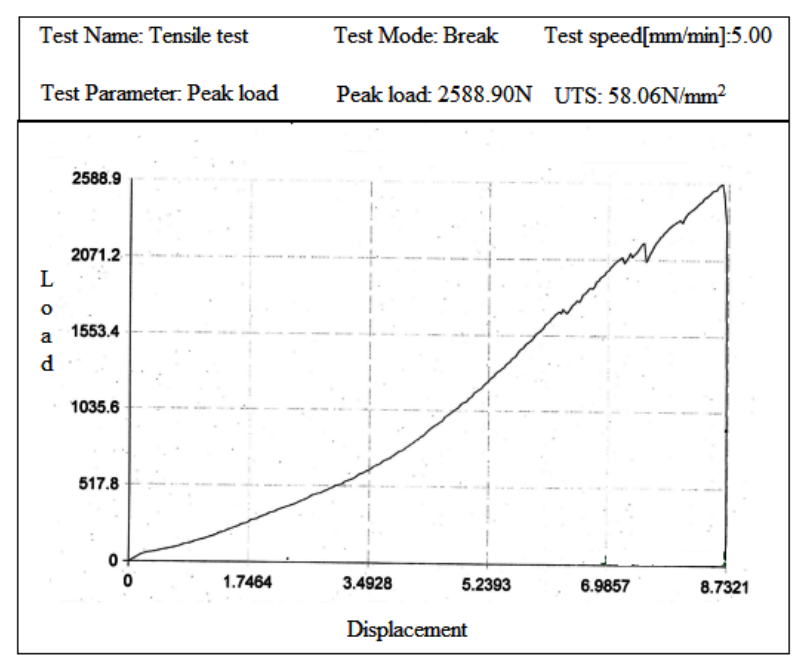

Figure 15: Tensile test graph for 3layer of glass fibre for $30^{\circ}$ orientation. 


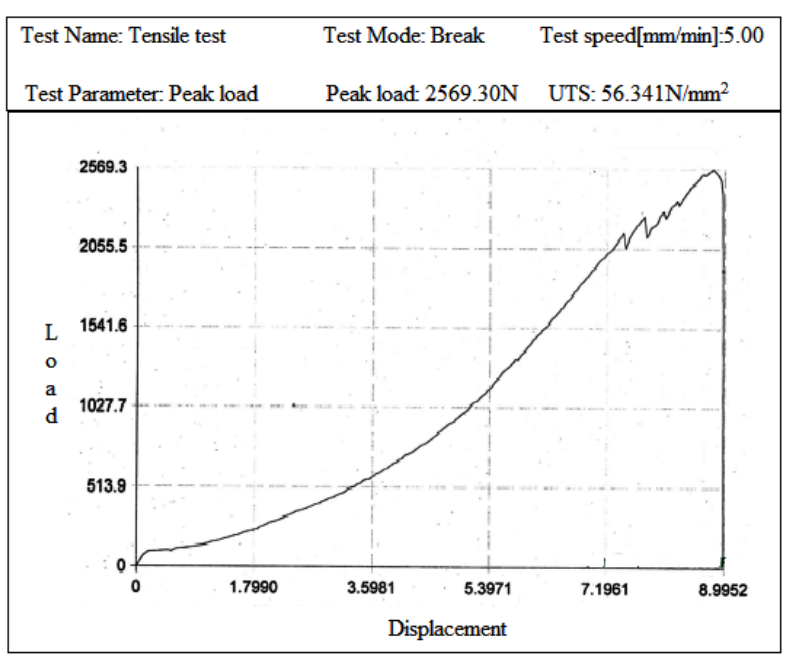

Figure 16: Tensile test graph for 3layer of glass fibre for $60^{\circ}$ orientation.



Figure 17: Tensile test graph for 3layer of glass fibre for $90^{\circ}$ orientation

Table 1: Tensile test results

\begin{tabular}{|l|l|l|}
\hline & $\begin{array}{l}\text { Peak Load } \\
\text { In N }\end{array}$ & $\begin{array}{l}\text { UTS } \\
\text { In N/mm }\end{array}$ \\
\hline For 1Layer- $30^{\circ}$ & 774.700 & 19.354 \\
\hline $60^{\circ}$ & 568.800 & 12.234 \\
\hline $90^{\circ}$ & 1304.300 & 25.959 \\
\hline For 2Layers- 30 & 1392.500 & 33.156 \\
\hline $60^{\circ}$ & 1304.300 & 27.678 \\
\hline $90^{\circ}$ & 1951.500 & 43.389 \\
\hline For 3Layers- 30 & 2588.950 & 58.06 \\
\hline $60^{\circ}$ & 2569.300 & 56.341 \\
\hline $90^{\circ}$ & 3187.100 & 72.378 \\
\hline
\end{tabular}

\section{B. Compression Test:}

Compression test is conducted for the prepared specimens for 1 layer, 2 layers and for 3 layers glass fibres for different orientations. The graphs are shown below

For 1 layer of glass fibre.

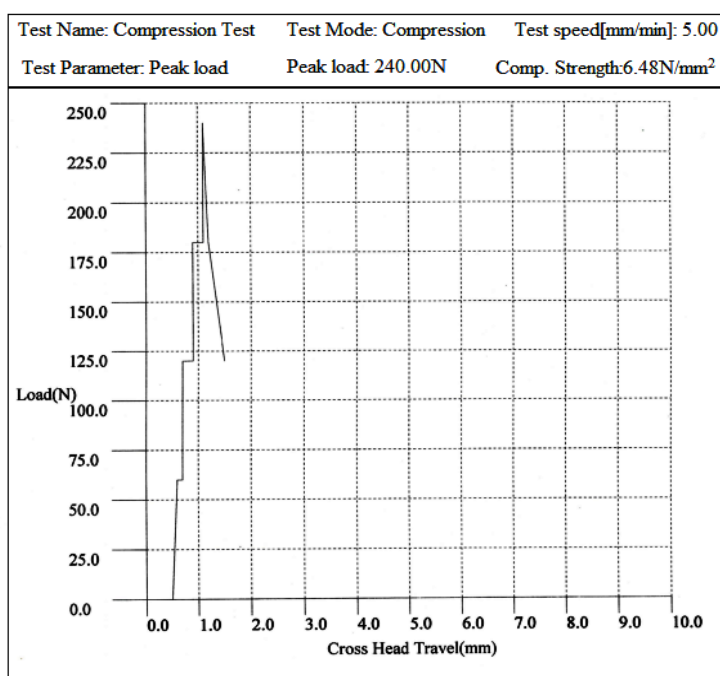

Figure 18: Compression test graph for 1layer of glass fibre for $30^{\circ}$ orientation.

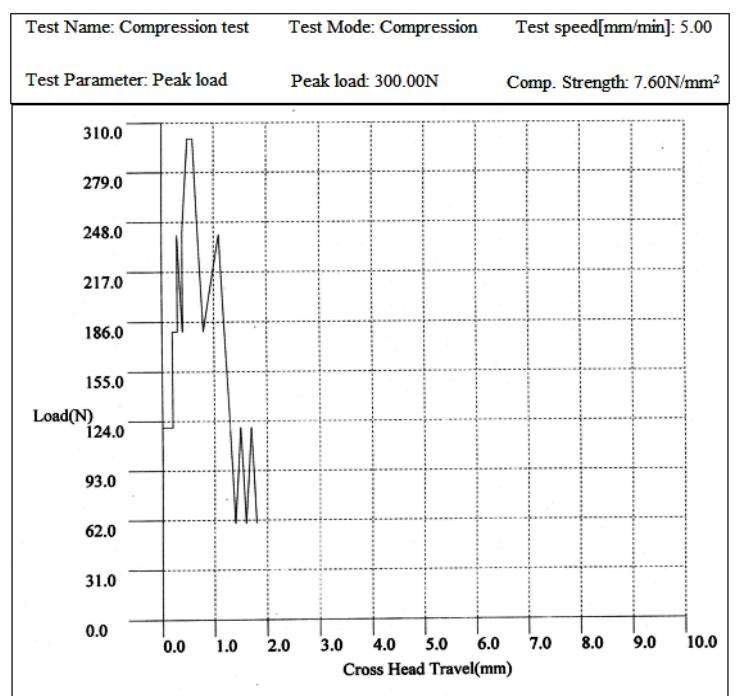

Figure 19: Compression test graph for 1layer of glass fibre for $60^{\circ}$ orientation.



Figure 20: Compression test graph for 1layer of glass fibre for $90^{\circ}$ orientation. 


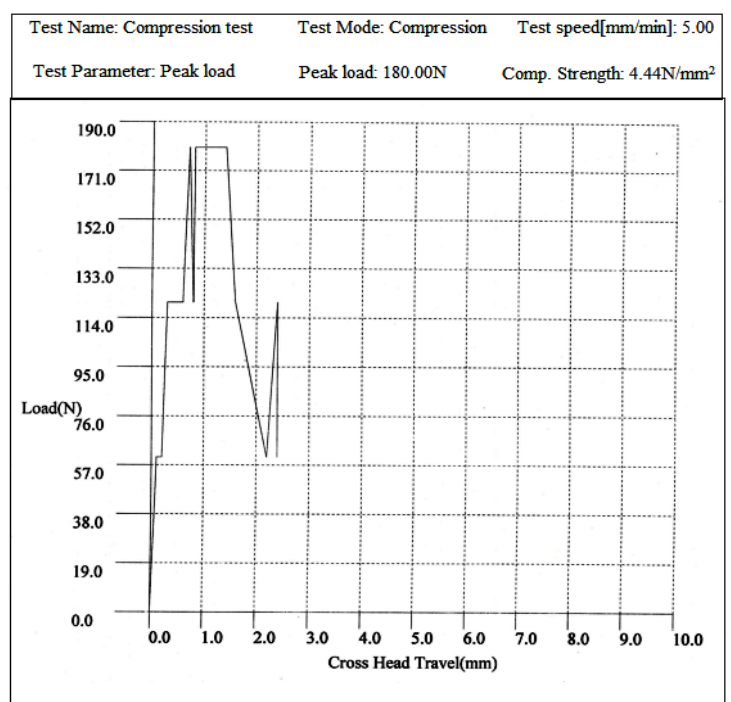

Figure 21: Compression test graph for 2layer of glass fibre for $30^{\circ}$ orientation.

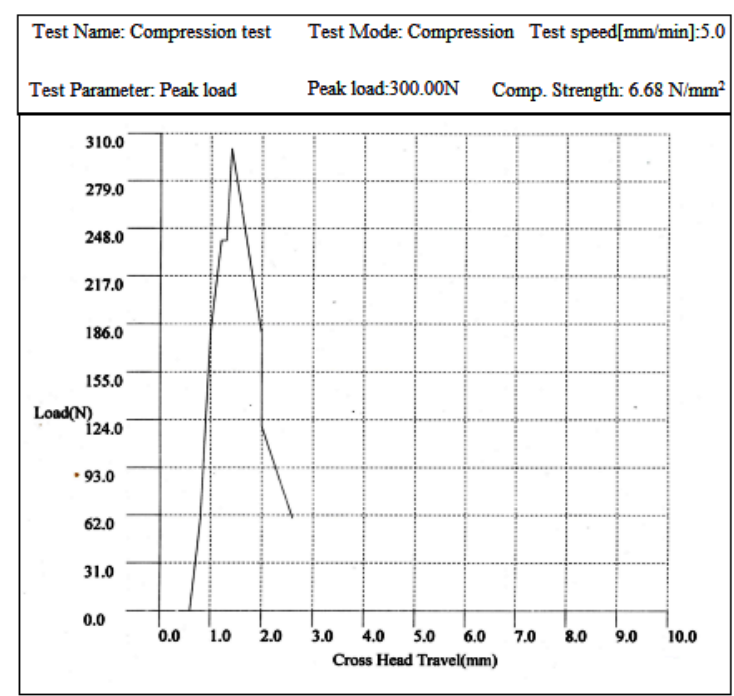

Figure 21: Compression test graph for 2layer of glass fibre for $60^{\circ}$ orientation.

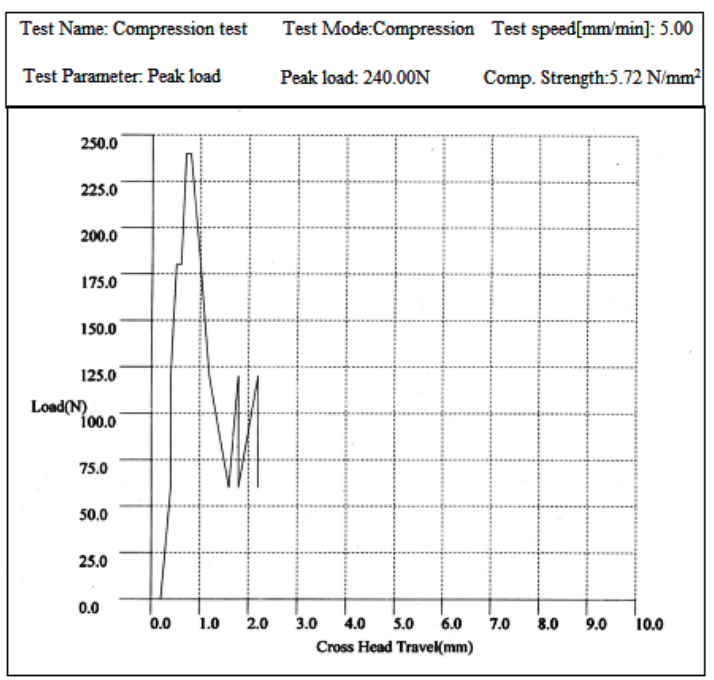

Figure 22: Compression test graph for 2layer of glass fibre for $90^{\circ}$ orientation.

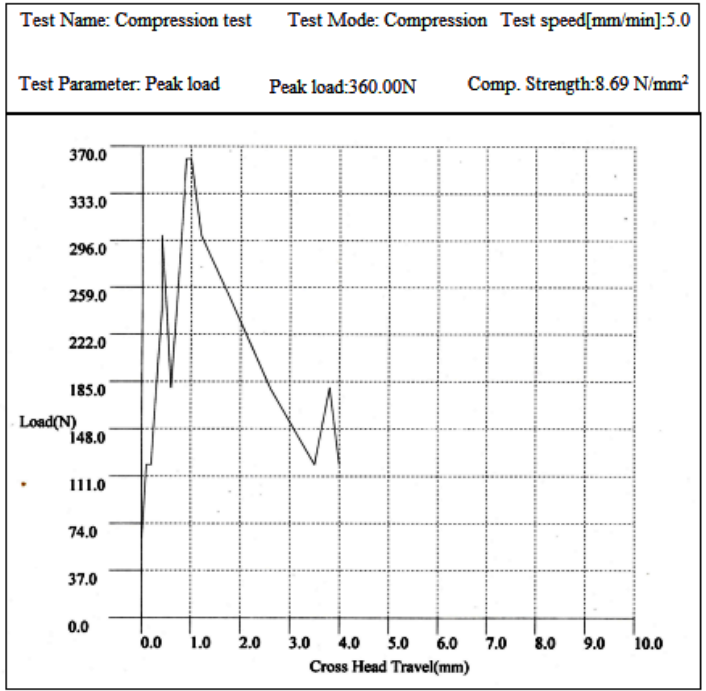

Figure 23: Compression test graph for 3layer of glass fibre for $30^{\circ}$ orientation.



Figure 24: Compression test graph for 3layer of glass fibre for $60^{\circ}$ orientation.

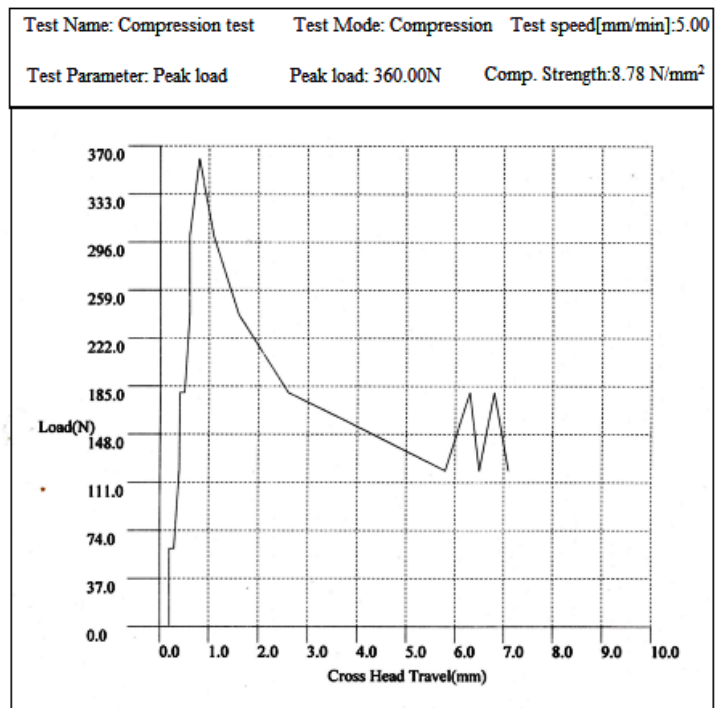

Figure 25: Compression test graph for 3layer of glass fibre for $90^{\circ}$ orientation. 
Table 2: Compression test results

\begin{tabular}{|l|l|l|}
\hline & $\begin{array}{l}\text { Peak Load } \\
\text { In N }\end{array}$ & $\begin{array}{l}\text { Comp. Strength } \\
\text { In N/mm }\end{array}$ \\
\hline $\begin{array}{l}\text { For 1Layer- } \\
30^{\circ}\end{array}$ & 240.00 & 6.48 \\
\hline $60^{\circ}$ & 300.00 & 7.60 \\
\hline $90^{\circ}$ & 240.00 & 5.61 \\
\hline For 2Layers-30 & 180.00 & 4.44 \\
\hline $60^{\circ}$ & 300.00 & 6.68 \\
\hline $90^{\circ}$ & 240.00 & 5.72 \\
\hline For 3Layers-30 & 360.00 & 8.69 \\
\hline $60^{\circ}$ & 400.00 & 9.69 \\
\hline $90^{\circ}$ & 360.00 & 8.78 \\
\hline
\end{tabular}

\section{Bending Test:}

Bending test is conducted for the prepared specimens for 1 layer, 2 layers and for 3 layers glass fibres for different orientations. The test speed was $5 \mathrm{~mm} / \mathrm{min}$ and the graph generated is shown below



Figure 26: Bending test graph for 1layer of glass fibre for $30^{\circ}$ orientation.

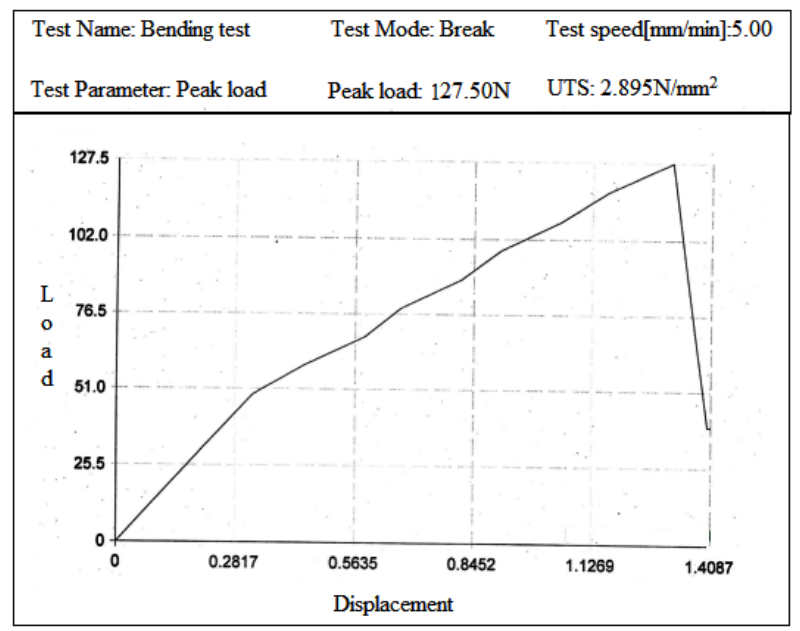

Figure 27: Bending test graph for 1layer of glass fibre for $60^{\circ}$ orientation.

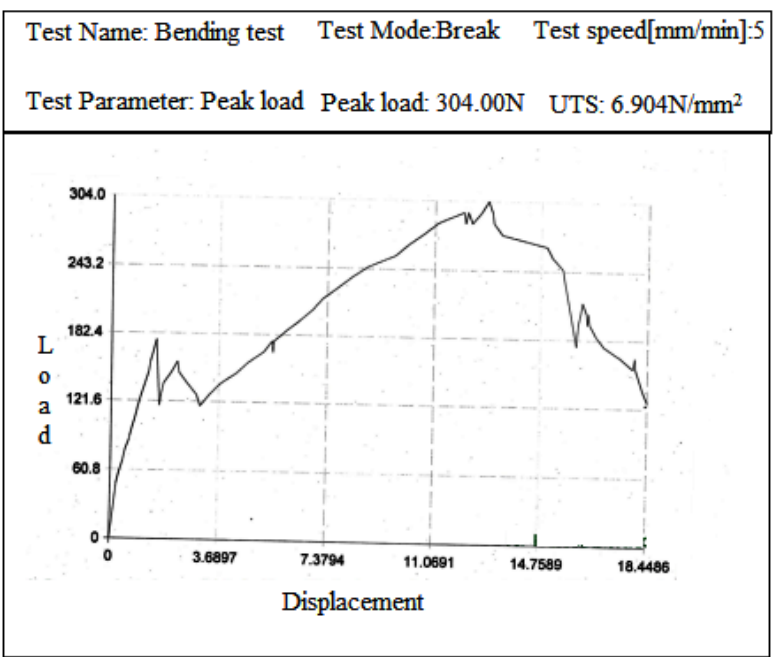

Figure 27: Bending test graph for 1layer of glass fibre for $90^{\circ}$ orientation.

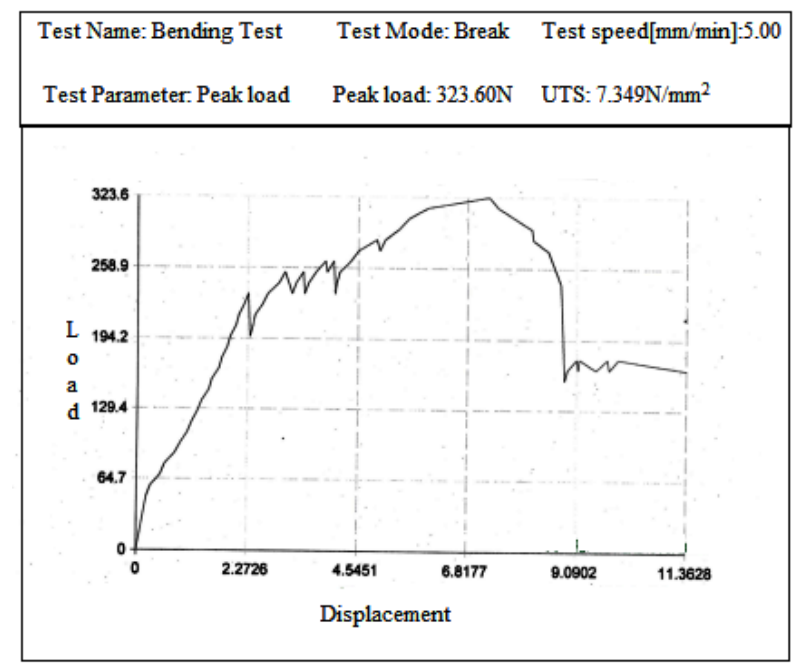

Figure 28: Bending test graph for 2layer of glass fibre for $30^{\circ}$ orientation.

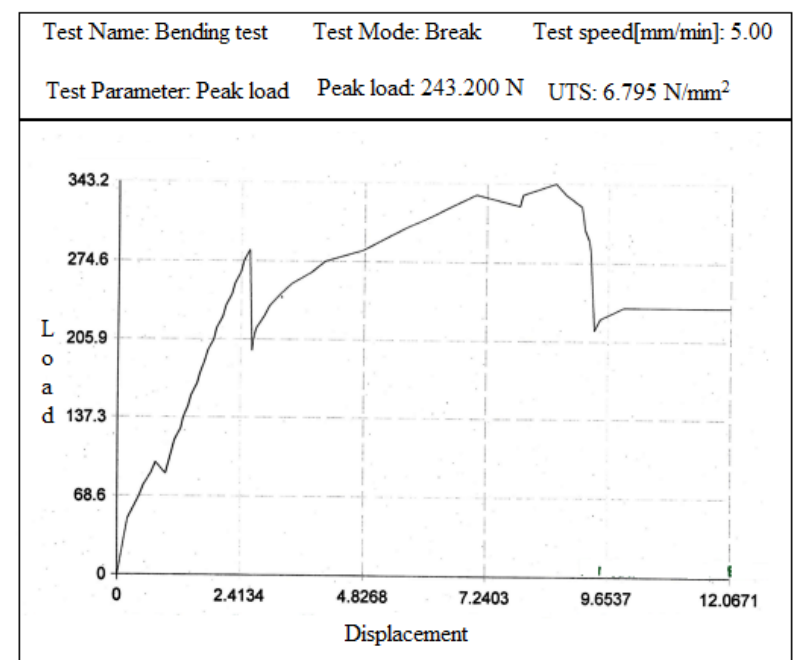

Figure 29: Bending test graph for 2layer of glass fibre for $60^{\circ}$ orientation. 


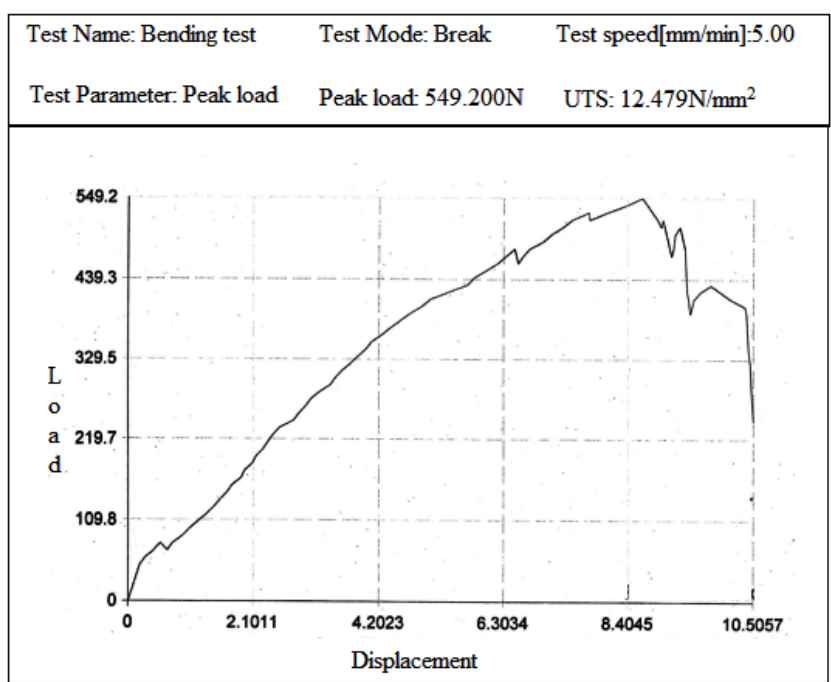

Figure 30: Bending test graph for 2layer of glass fibre for $90^{\circ}$ orientation.



Figure 31: Bending test graph for 3layer of glass fibre for $30^{\circ}$ orientation.

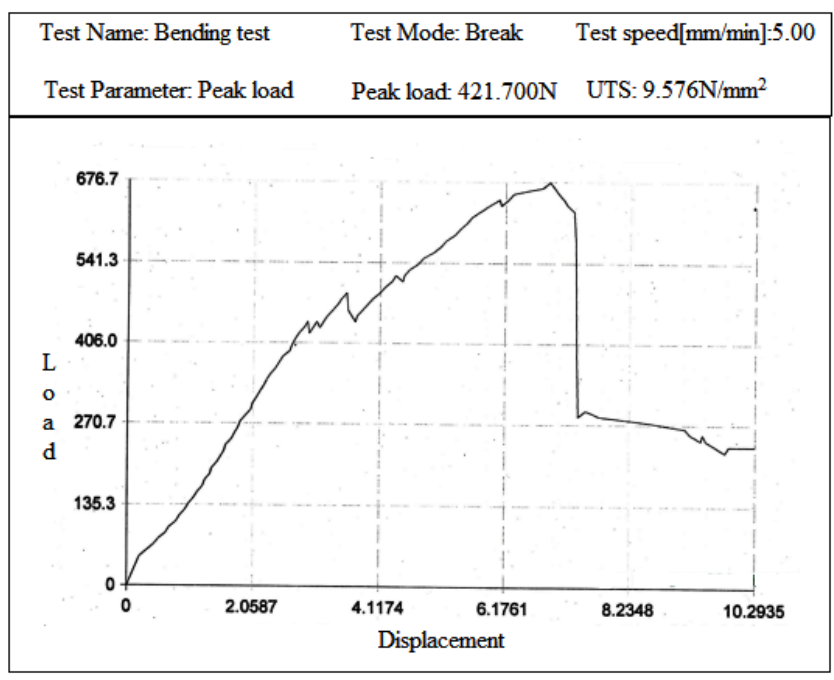

Figure 32: Bending test graph for 3layer of glass fibre for $60^{\circ}$ orientation.

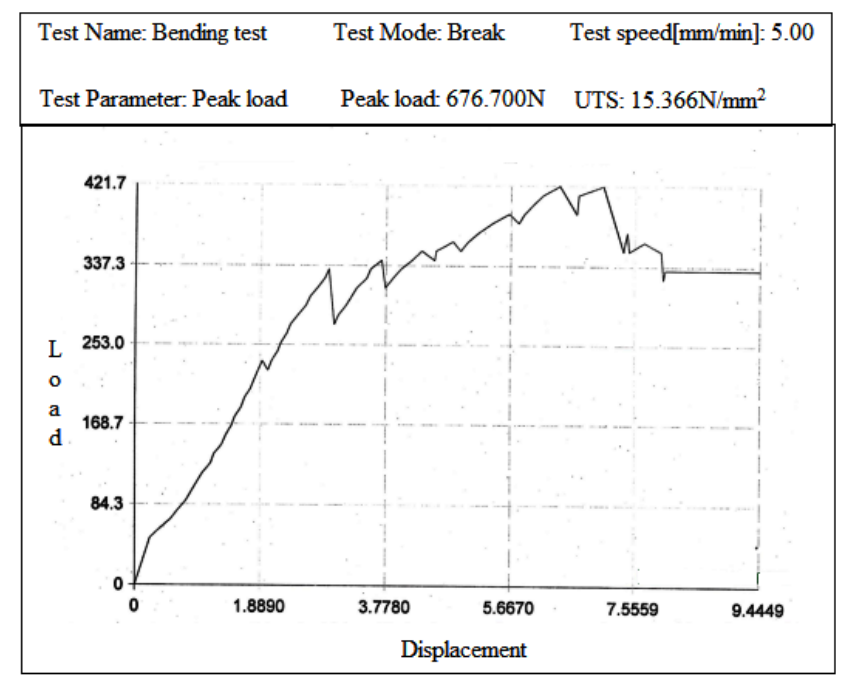

Figure 33: Bending test graph for 3layer of glass fibre for $90^{\circ}$ orientation.

Table 3: Bending test results

\begin{tabular}{|c|c|c|}
\hline & $\begin{array}{l}\text { Peak Load } \\
\text { In N }\end{array}$ & $\begin{array}{l}\text { UTS } \\
\text { In N/mm }{ }^{2}\end{array}$ \\
\hline For 1Layer- $30^{\circ}$ & 215.700 & 4.89 \\
\hline $60^{\circ}$ & 127.500 & 2.895 \\
\hline $90^{\circ}$ & 304.00 & 6.904 \\
\hline For 2Layers- $30^{\circ}$ & 383.600 & 8.349 \\
\hline $60^{\circ}$ & 343.200 & 7.795 \\
\hline $90^{\circ}$ & 549.200 & 12.471 \\
\hline For 3Layers $-30^{\circ}$ & 572.700 & 13.468 \\
\hline $60^{\circ}$ & 421.700 & 9.576 \\
\hline $90^{\circ}$ & 676.700 & 15.366 \\
\hline
\end{tabular}

\section{DISCUSSION}

A. Tensile test: The tensile strength for the different orientation has been depicted in the form of graph below,

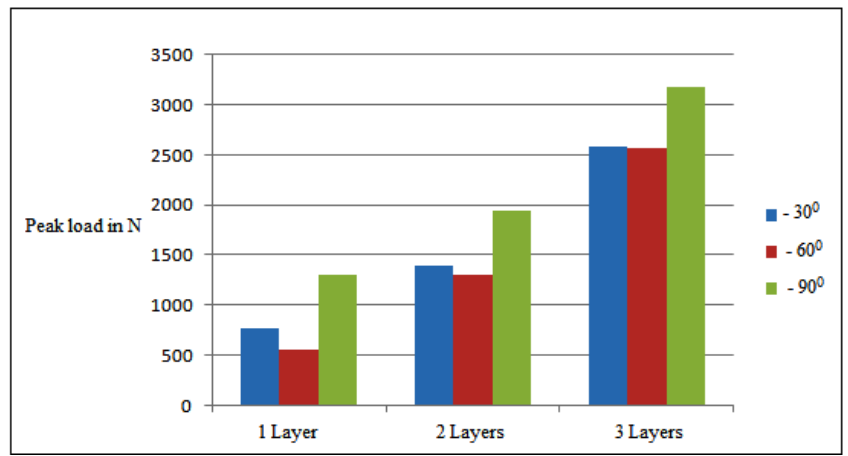

Figure 34: Graph for Tensile test Peak load (N) vs. Number of layers of Glass fibre. 


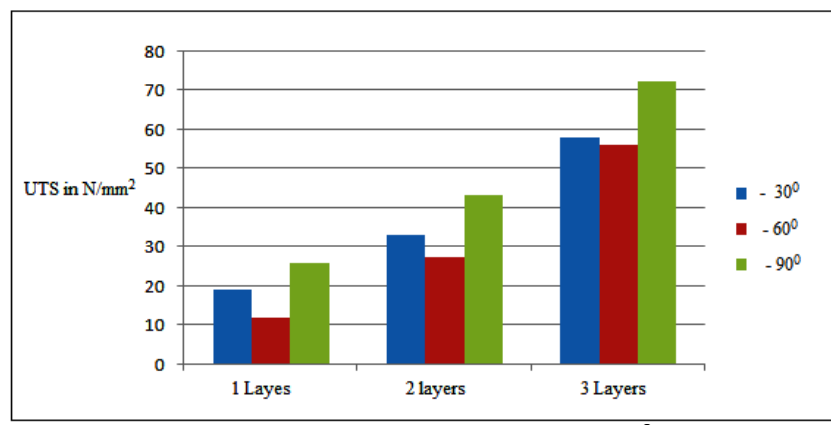

Figure 35:Graph for Tensile test UTS $\left(\mathrm{N} / \mathrm{mm}^{2}\right)$ vs. Number of layers of Glass fibre.

The results obtained from the tensile test carried on 1, 2 and 3 layers of glass fibre for $30^{\circ}, 60^{\circ}$ and $90^{\circ}$ orientation, it is observed from the graph that the peak load is more for $30^{\circ}$ and $90^{\circ}$ orientations. And while comparing for $30^{\circ}$ and $90^{\circ}$, the peak load and Ultimate tensile strength is maximum for $90^{\circ}$ orientation.

$>$ Comparing all the layers of glass fibres for $30^{\circ}, 60^{\circ}$ and $90^{\circ}$ orientation it is observed that the 3 layer glass fibre for $90^{\circ}$ orientation withstand maximum peak load and Ultimate tensile strength than the rest of the samples.

B. Compression test: The compression strength for the different orientation has been depicted in the form of graph below,

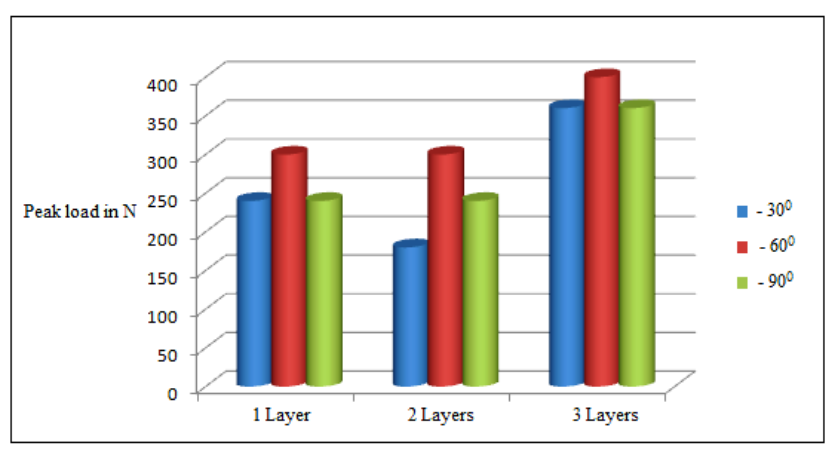

Figure 36 : Graph for Compression test Peak load (N) vs. Number of layers of Glass fibre

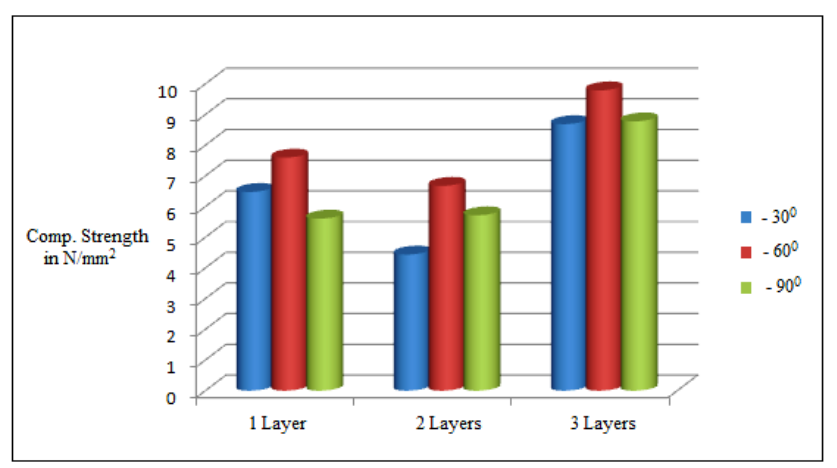

Figure 37 : Chart for Compressive strength in UTS $\left(\mathrm{N} / \mathrm{mm}^{2}\right)$ vs. Number of layers of Glass fibre

$>$ The results shows that Compression test carried on 1, 2 and 3 layers of glass fibre for $30^{\circ}, 60^{\circ}$ and $90^{\circ}$ orientations, it is observed that the peak load and compressive strength is more for $60^{\circ}$ orientation than $30^{\circ}$ and $90^{\circ}$ orientations.

$>$ Comparing all the layers of glass fibres for $30^{\circ}, 60^{\circ}$ and $90^{\circ}$ orientation it is observed that the 3 layer glass fibre for $60^{\circ}$ orientation withstand maximum peak load and Compressive strength than the rest of the samples.

C. Bending test: The bending strength for the different orientation has been depicted in the form of graph below,



Figure 38: Graph for bending test Peak load (N) vs. Number of layers of Glass fibre

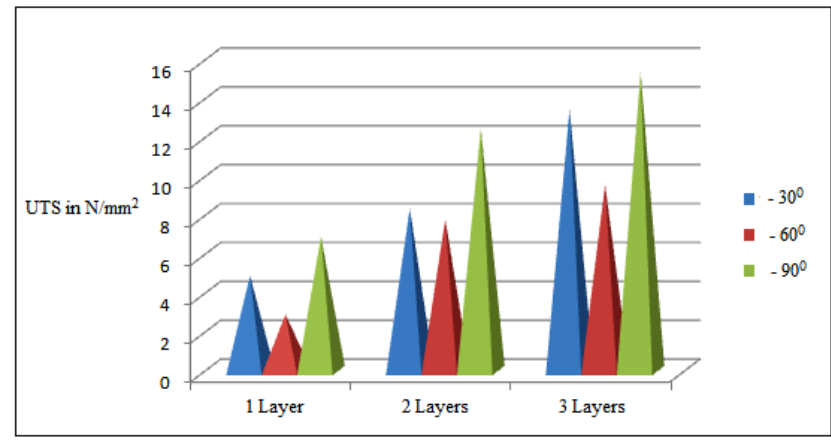

Figure 39: Graph for bending test UTS $\left(\mathrm{N} / \mathrm{mm}^{2}\right)$ vs. Number of layers of Glass fibre

The Results obtained from the Bending test carried on $30^{\circ}$, $60^{\circ}$ and $90^{\circ}$ orientation of glass fibre using polyester resin we observed that,

$>\quad$ The results obtained from the Bending test carried on 1,2 and 3 layers of glass fibre for $30^{\circ}, 60^{\circ}$ and $90^{\circ}$ orientation, it is observed from the graph that the peak load and UTS is more for $30^{\circ}$ and $90^{\circ}$ orientations. And while comparing for $30^{\circ}$ and $90^{\circ}$, the peak load and UTS is maximum for $90^{\circ}$ orientation for 1 layer glass fibre.

$>$ Comparing all the layers of glass fibres for $30^{\circ}, 60^{\circ}$ and $90^{\circ}$ orientation it is observed that the 3 layer glass fibre for $90^{\circ}$ orientation withstand maximum peak load and UTS than the rest of the samples.

Pin-on-disc wear test: For 1 Layer glass fibre for different orientation the wear is, 


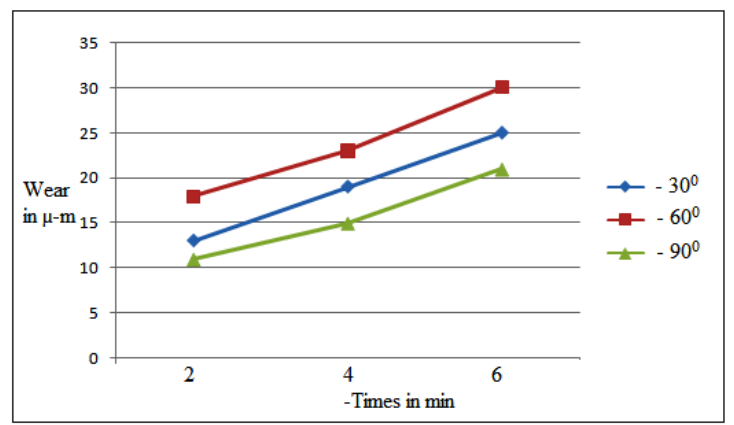

Figure 40: Graph for wear vs. Time for 1 layer of glass fibre for different orientation.

By considering the above graph it is seen that the wear for 1 layer glass fibre for different orientations increases as the time increases. As the tensile strength is more for $30^{\circ}$ and $90^{\circ}$ orientations, the wear is less as shown in the above figure. As the tensile strength is less for $60^{\circ}$ orientation, the wear is comparatively more. The tensile strength is more for $90^{\circ}$ orientations as compare to $30^{\circ}$ and $60^{\circ}$ hence the wear rate is less for $90^{\circ}$ as compare to $30^{\circ}$ and $60^{\circ}$.

For 2 Layers glass fibre for different orientation the wear is,



Figure 41: Graph for wear vs. Time for 2 layer of glass fibre for different orientation.

By considering the above graph it is seen that the wear for 2 layers glass fibre for different orientations increases as the time increases. As the tensile strength is more for $30^{\circ}$ and $90^{\circ}$ orientations, the wear is less as shown in the above figure. As the tensile strength is less for $60^{\circ}$ orientation, the wear is comparatively more. The tensile strength is more for $90^{\circ}$ orientation as compare to $30^{\circ}$ and $60^{\circ}$ hence the wear rate is less for $90^{\circ}$ as compare to $30^{\circ}$ and $60^{\circ}$.

For 3 Layers glass fibre for different orientation the wear rate and Frictional force are:

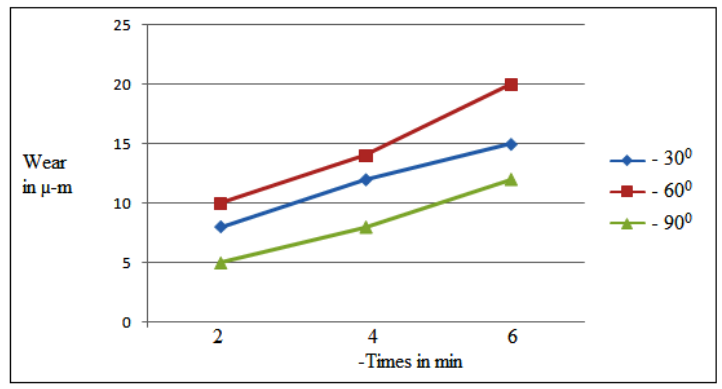

Figure 43: Graph for wear vs. Time for 3 layer of glass fibre for different orientation.
By considering the above graph it is seen that the wear for 3 layers glass fibre for different orientations increases as the time increases. As the tensile strength is more for $30^{\circ}$ and $90^{\circ}$ orientations, the wear is less as shown in the above figure. As the tensile strength is less for $60^{\circ}$ orientation, the wear is comparatively more. The tensile strength is more for $90^{\circ}$ orientation as compare to $30^{\circ}$ and $60^{\circ}$ hence the wear rate is less for $90^{\circ}$ as compare to $30^{\circ}$ and $60^{\circ}$.

\section{CONCLUSION}

\section{A. TENSILE:}

* We consider 1, 2 and 3 Layers of Glass fibre laminate composite for the orientation of $30^{\circ}, 60^{\circ}$ and $90^{\circ}$ angles reinforced in polyester matrix composite for tensile experimental test and the results shows that the Peak load and Ultimate Tensile strength is maximum for 3 layers of glass fibre for $90^{\circ}$ orientation.

\section{B. COMPRESSION:}

* We consider 1, 2 and 3 Layers of Glass fibre laminate composite for the orientation of $30^{\circ}, 60^{\circ}$ and $90^{\circ}$ angles reinforced in polyester matrix composite for Compression experimental test and the results shows that the peak load and Compressive strength is more for $60^{\circ}$ orientation for 3 layers of the glass fibre.

\section{BENDING:}

* We consider 1, 2 and 3 Layers of Glass fibre laminate composite for the orientation of $30^{\circ}, 60^{\circ}$ and $90^{\circ}$ angles reinforced in polyester matrix composite for bending experimental test and the results shows that the Peak load and UTS is maximum 3 layers of glass fibre for $90^{\circ}$ orientations.

\section{PIN-ON-DISC WEAR TEST:}

* We consider 1, 2 and 3 Layers of Glass fibre laminate composite for the orientation of $30^{\circ}, 60^{\circ}$ and $90^{\circ}$ angles reinforced in polyester matrix composite for wear test and by considering the results it is seen that the wear rate increases as the time increases and as the tensile strength is more for $30^{\circ}$ and $90^{\circ}$ orientation, for all the layers of glass fibres wear rate is less as compare to $60^{\circ}$ orientation.

\section{REFERENCES}

[1]. Autar K.Kaw, mechanics of composite materials, Taylor \& francis group LLC, 2 edition, 2006

[2]. Shahzad Alam, Farzana Habib; A Paper Titled Effect of Orientation of Glass Fibre on Mechanical Properties of GRP Composite, Volume 32, 2010.

[3]. Prashant Banakar, H.K.Shivananda; Influence of Fibre orientation and Thickness on Tensile properties of laminated polymer composites, ISSN 2229-6107, 2012, pp 61-68

[4]. Seyyedvahid Mortazavian, Ali fatemi; Effect of Fibre orientation and anisotropy on tensile strength and elastic modulus of short fibre reinforced polymer 
composite; composite: part B72(2015) 116-129, Oct 2014

[5]. Puttaswamaiah. S Maruthi B. H; A Paper titled Synthesis and Characterization of calcium silicate Reinforced Polyester Composites, International Journal of Engineering and Technology, volume 3, May- 2014,

[6]. Rajmohan $\mathrm{T}$ Koundinya $\mathrm{U}$ K; Evaluation of Mechanical Properties of Nano filled Glass fibre Reinforced composite; international conference on advanced nonmaterial's and emerging Engineering Technology,2013 pg 112-155

[7]. Nafisa Gull, Shahzad Maqsood khan, Tahir jamil, Mahumad Shafiq; Synthesis and Characterization of Zinc oxide (Zno) filled glass fibre reinforced polyester composite, Material and Design 67(2015)313-317, May 2014

[8]. Author- M Ramesh, K Palanikumar, K Hemachandra reddy, Title- Mechanical Properties evaluation of sisal-jute glass Fibre reinforced polyester composites, composites: Part B 48 (2013) 1-9

[9]. H. Unal, A. Mimaroglu, H. Ekiz, U. Kadioglu', Sliding friction and wear behaviour of polytetrafluroethylene and its composites under dry condition', Material and Design 25(2004)239-245

[10]. A.A. El-Sayed, M.G. El-Sherbiny, G.A. Aggag, A.S. Abo-El-Ezz', Friction and wear properties of polymeric composites materials for bearing applications', National institute for standard, Wear 184(1995) 45-53 